\title{
História da historiografia como analítica da historicidade*
}

\author{
History of historiography as an analysis of historicity
}

\author{
Valdei Lopes de Araujo \\ valdei354@gmail.com \\ Professor adjunto \\ Universidade Federal de Ouro Preto \\ Rua do Seminário, s/n - Centro \\ 35420-000 - Mariana - MG \\ Brasil
}

\section{Resumo}

Neste artigo analiso os contornos teóricos da história da historiografia, desde suas possibilidades como uma subdisciplina acadêmica, sua evolução recente no contexto brasileiro até as vantagens e riscos de sua institucionalização. Tento ainda pensar o campo de fenômenos, a abertura do tempo histórico, que poderia fundamentar uma história da historiografia como analítica da historicidade. Argumento, a partir da definição de historicidade em Heidegger, que tal analítica poderia permitir uma ampliação substancial do escopo de uma história da historiografia como atividade de fronteira, capaz de contribuir para a recuperação de certa experiência da história.

\section{4}

\section{Palavras-chave}

Historicidade; Historiografia; Clima histórico.

\begin{abstract}
This paper analyzes some theoretical foundations of the history of historiography, from its possibilities as an academic sub-discipline, its recent evolution in the Brazilian context and the advantages and risks of its institutionalization. It also tries to think about the field of phenomena the opening of historical time - which could be taken as the foundation of a History of Historiography as an analysis of historicity. From Heidegger's definition of historicity it argues that an analysis of historicity could substantially enlarge the aims of a history of historiography taken as a border activity capable of contributing to the recovery of some dimensions of historical experience.
\end{abstract}

\section{Keywords}

Historicity; Historiography; Historical atmosphere.

Recebido em: 22/4/2013

Aprovado em: 17/6/2013

\footnotetext{
* Este pequeno texto tem recebido a atenção generosa de tantos colegas, com os quais tive a possibilidade de dialogar, que corro o risco de esquecer alguém nestes agradecimentos. No entanto, preciso esclarecer que foi escrito para a I Jornada de História da Historiografia, promovida na UFRGS, em 2012, por Temístocles Cezar e Fernando Nicolazzi, aos quais sou imensamente grato pelo convite e a interlocução crítica sempre valiosa. Antes, durante e depois, agradeço a leitura e o incentivo de Mateus Henrique de Faria Pereira, leitor exigente e inquieto. Aos colegas, alunos e docentes do Núcleo de Estudos em História da Historiografia e Modernidade (NEHM) da UFOP pelo convívio incrivelmente rico e estimulante. Entre 2012 e 2013, tive a sorte de ministrar uma disciplina sobre Ser e tempo na companhia de Luisa Rauter Pereira e Marcelo Rangel, um momento de grande alegria e aprendizado. Por fim, a pesquisa tem sido conduzida no âmbito do projeto de apoio a grupos emergentes da Fapemig, PRONEM, intitulado: "Historiografia e modernidade: variedades do discurso histórico".
} 


\section{Em busca de definições e limites}

Mesmo sendo uma prática em expansão entre os historiadores, a ponto de ser possível usarmos a expressão "virada historiográfica" para fazermos referência a ela, a história da historiografia tem recebido pouca atenção quanto a seus limites teóricos e definição, ao menos se ignorarmos os textos-manifestos que eventualmente relançam o campo, o que, de certa forma, não deixa de ser o caso deste que segue. Ao contrário da Teoria da História, que tem uma identidade construída, a História da Historiografia não raro mal consegue ser separada de seu objeto mais evidente, a escrita da história. Quem já teve de ministrar a disciplina em algum curso de graduação sabe o quanto é difícil estabelecer as fronteiras entre a escrita da história (historiografia) e o seu estudo crítico, a história da historiografia. A indecisão na forma de se referir a essa atividade intelectual (historiografia, história da história, história da historiografia) reflete a carência de problematização teórica sobre o seu estatuto. Não é de se estranhar, portanto, que, mesmo em uma obra abrangente e sistemática como a de Jörn Rüsen, encontremos pouca ajuda para compreender o que fazemos quando nos dedicamos a pesquisar e escrever história da historiografia, pois não é claro o lugar que poderia ocupar na "matriz do pensamento histórico" (RÜSEN 2009, p. 188). Em entrevista recente, François Hartog apenas confirmou o valor ambíguo que a reflexão teórica tem na tradição tardia dos Annales, excessivamente confiante em um ofício do historiador que se legitima como pura prática (RODRIGUES; NICOLAZZI 2012). Trata-se de uma espécie de vício de origem e de uma época, os anos 1920 na França, quando e onde se sonhou a história como um tipo de ciência que hoje nem mesmo as ciências acreditam ser, isto é, como uma prática/técnica tão confortável no interior do Estado social moderno que dispensaria pensar suas condições teóricas e institucionais, tarefa que talvez se poderia delegar a outros técnicos como sociólogos e filósofos. No entanto, há muito essas disciplinas abandonaram esse serviço. Uma historiografia que espere delas o fundamento de sua consistência intelectual permanecerá na indigência quanto a sua autocompreensão.

Desde que publiquei em 2006 um artigo na revista Locus intitulado "Sobre o lugar da história da historiografia como disciplina autônoma", tenho tido regularmente de responder pelo fato de ter dado um título ambicioso para um texto modesto (ARAUJO 2006). Embora não tenha usado ali a palavra "campo", desde então, com o crescimento da quantidade e qualidade das pesquisas em história da historiografia no Brasil, essa palavra adquiriu a qualidade de um rótulo provisório para referir a um conjunto muito complexo de fenômenos. Proponho suspender provisoriamente o uso da expressão "campo" em um exercício de retorno às "coisas mesmas" que esse rótulo encobre. Acredito que seja possível mobilizar categorias mais precisas para pensar o que estamos fazendo quando nos dedicamos à história da historiografia.

Não seria despropositado inicialmente partir da afirmação de que as pesquisas que realizamos podem ser situadas no âmbito da historiografia modernamente constituída, não apenas pelo fato de serem produzidas em um âmbito acadêmico, mas também por reivindicarem em maior ou menor 
grau o pertencimento ao campo científico. Independentemente das diferenças de métodos, abordagens ou objetos, todos mobilizamos com maior ou menor intensidade as ferramentas do método crítico, que continuou a ser uma das marcas de distinção da prática historiográfica, mesmo que não goze da mesma relevância e prestígio em todas as subdisciplinas e que tenha ele mesmo sofrido importantes transformações nos últimos duzentos anos.

Como parte da disciplina histórica, a pesquisa em história da historiografia precisa ainda demonstrar suas condições de autonomia para poder reivindicar o estatuto de uma subdisciplina, e chegados a este ponto já avançamos um pouco com relação às formulações anteriores que trabalhavam com as categorias "disciplina" e "campo". No entanto, essa afirmação é ainda vazia de conteúdos. Afinal, não poderia ser a historiografia apenas o objeto de uma história especial que poderia ser pesquisada segundo as perspectivas de diversas outras subdisciplinas? A resposta a essa questão não deveria ser a desqualificação de outras abordagens históricas (ou mesmo literárias, sociológicas, antropológicas etc.) da historiografia, mas a demonstração de uma abordagem ou subdisciplina que pudesse dimensionar melhor o que é próprio do fenômeno historiográfico com relação a outras famílias de fenômenos.

De que fenômenos ou conjunto de fenômenos estamos falando quando pesquisamos e escrevemos sobre a historiografia? É o que tentarei esclarecer na seção seguinte. Antes de avançar, porém, talvez seja prudente fazer alguns apontamentos sobre outra categoria que utilizamos para nos reunir e reunir o 36 que fazemos e que recentemente obteve uma fortuna melhor do que as palavras "campo" ou "disciplina". Trata-se da noção de "comunidade".

Que tipo estranho de comunidade formaríamos se, na definição sociológica clássica do termo, as condições para a sua existência parecem estar bem distantes da nossa? Certamente estamos diante de uma aproximação metafórica do fenômeno, mas que, como tal, pode revelar elementos importantes. Mais do que afirmar a existência de alguma estranha comunidade, o que talvez o uso da palavra revele é a emergência de novas condições político-institucionais para a pesquisa em história da historiografia no Brasil.

No contexto em que foi produzido o artigo de 2006, que fazia parte da minha tese, escrita no começo deste século, procurava responder à percepção de que a Teoria da História e a História da Historiografia eram disciplinas que passavam por um processo duplo de esvaziamento acadêmico: apesar da enunciação monumental de sua matriz por José Honório Rodrigues nos anos 1970, o estabelecimento da historiografia em padrões universitários entre os anos 1980 e 1990 não tinha tornado realidade aquele desenho. Dentre os muitos motivos que poderiam ser apontados, mencionarei apenas um: a hegemonização de um padrão historiográfico que priorizou a pesquisa empírica e o método em detrimento da teoria e da autorreflexão. O incentivo crescente à subespecialização levou importantes departamentos a se reorganizarem de forma a priorizar as subdisciplinas mais pragmaticamente ligadas à pesquisa de pós-graduação, em geral concentradas, primeiro, sob a designação de História Social/Econômica e, depois, sob a denominação de História Cultural. Em algum 
momento, pareceu que os estudos em história da historiografia poderiam ser diluídos no interior de um grande e impreciso universo chamado história cultural. As consequências institucionais eram visíveis: faltavam linhas de pesquisa e pesquisadores capazes de formar jovens doutores, e as vagas das disciplinas do grande setor de teoria imaginado por José Honório, ou eram ocupadas por não especialistas, ou eram extintas. Mesmo hoje não é raro encontrar cursos de graduação em História cuja matriz disciplinar apresenta apenas uma ou duas disciplinas obrigatórias do setor. Mais recentemente - como resultado do esforço de formação de alguns poucos abnegados dos anos 1980 e 1990 -, uma nova geração de doutores tem permitido a ocupação desses espaços que sobreviveram graças a pesquisadores especialistas que se dedicam a produzir em sintonia com sua atividade didática. ${ }^{1}$

Não quero dizer com isso que devemos iniciar uma cruzada para reintroduzir nos currículos essas disciplinas, em especial como obrigatórias, mas, sim, que devemos procurar estratégias de ampliação do diálogo com outros ramos da historiografia, diálogo esse um tanto comprometido nos anos 1980 e 1990 pela crise dos grandes paradigmas e a busca de novas linguagens e referenciais. Como as disciplinas teóricas estiveram no centro desse furacão, foi natural a formação de certo abismo entre suas abordagens e linguagens em comparação com campos mais tradicionais da pesquisa. Hoje, esse cenário parece estar se revertendo, e vemos grandes departamentos com programas de pósgraduação reconhecidos buscando atrair pesquisadores em teoria e história da historiografia por identificarem nesse setor um aporte essencial à formação de recursos humanos e à pesquisa. O futuro dessa relação dependerá de nossa capacidade de assumir e priorizar o diálogo com as demais subdisciplinas históricas.

Portanto, a presença de uma "comunidade" que começamos a sentir é um dos resultados desse processo descontínuo de expansão. Mas esse crescimento por si só não estaria produzindo efeitos se, mais recentemente, não tivesse sido acompanhado pelo surgimento de espaços regulados de convivência e conversação, e aqui me refiro particularmente aos periódicos e eventos especializados, particularmente à criação, em 2009, da Sociedade Brasileira de Teoria e História da Historiografia (SBTHH).

Haveria, então, uma relação de causalidade direta entre o surgimento de uma "comunidade acadêmica" e uma disciplina? A relação certamente existe, mas sua causalidade não é tão simples de se estabelecer. Podem existir comunidades acadêmicas cuja força de reunião não seja um projeto disciplinar, mas interesses de pesquisa de outra natureza, sejam eles temáticos, cronológicos, focados em objetos ou programas comparativos. Um bom exemplo disso são os chamados Programas de Excelência (PRONEX) ou Projetos Temáticos, que agrupam comunidades ou redes de pesquisadores na realização de um projeto com prazo de encerramento e sem a cobertura de uma disciplina. No entanto, como uma disciplina pode existir sem algum vestígio de comunidade acadêmica? A existência 
de uma comunidade é uma das condições externas de sua autonomia: permite o diálogo e o debate sem o qual a pesquisa científica relevante não avança, cria as condições de recepção, comparação e juízo sobre a excelência dos trabalhos e que permitem avaliar em que medida eles respondem à história dos problemas e/ou criam as condições de memória e permanência tão desejáveis para a pesquisa nas Humanidades. A ausência ou precariedade dessa comunidade acadêmica ou de leitores especializados é uma das fontes da fragilidade da pesquisa em Teoria e História da Historiografia no Brasil em décadas passadas, fenômeno agravado pela exterioridade e efemeridade das agendas de investigação.

Mesmo que não se possa afirmar que a existência de uma comunidade acadêmica seja uma condição para a formação de uma disciplina, sua existência é altamente relevante e potencializadora. A recíproca também poderia ser afirmada, pois, no campo da ciência, uma comunidade é avaliada pela qualidade e relevância do conhecimento que produz. Isso não quer dizer que uma mesma comunidade não possa abrigar diferentes e diversos projetos disciplinares e mesmo margens nas quais uma disciplina não esteja em questão, círculos de maior mobilidade e transitividade. Talvez uma das formas para medir a potencialidade de uma comunidade dependa dessa relação tensa entre centros de identidade e margens ou aglomerados de interesses que gravitam e enriquecem o ambiente disciplinar. Acredito que definir a História da Historiografia como subdisciplina, bem como outras cujos germes já estão lançados no interior de nossa comunidade (Teoria da História; História Intelectual; Metodologia), é um modo decisivo de fortalecer os dois polos dessa equação.

Como parte da disciplina histórica, a pesquisa em história da historiografia precisa demonstrar continuamente suas condições de autonomia para que possa reivindicar o estatuto de uma subdisciplina. Essa afirmação não deveria acontecer pela desqualificação de outras abordagens historiográficas ou extra-historiográficas, mas pela demonstração de um enfoque que melhor pudesse dimensionar o que é próprio ao que poderíamos chamar de fenômenos historiográficos. Afinal, de quais fenômenos ou conjunto de fenômenos estamos falando quando pesquisamos e escrevemos sobre a historiografia? É o que tentaremos esclarecer a seguir. Tentarei, ainda que de modo provisório, encaminhar algumas respostas sobre o universo de fenômenos para os quais seria relevante e se poderia justificar teoricamente a existência de uma História da Historiografia como subdisciplina. Essa afirmação deveria nos levar a produzir um controle maior e mais complexo das agendas de investigação que poderíamos abrir, bem como daquelas que já estamos cumprindo.

\section{Um campo de fenômenos: os modos da historicidade}

A família de fenômenos com a qual essa disciplina poderia estabelecer uma relação decisiva poderia ser de antemão agrupada sob o rótulo "historicidade". Mas como se aproximar de uma definição razoavelmente operacional dessa categoria? O exercício que proponho desenvolver parte da contribuição de 
Heidegger, em Ser e tempo, ${ }^{2}$ na qual o autor define a historicidade como a estrutura do acontecer humano, ou a temporalizaçāo de sua temporalidade.

Não haveria espaço para recuperar todos os movimentos da reflexão de Heidegger sobre a temporalidade como estrutura, apenas lembro que está relacionada com a análise existencial do humano como um ser entre nascimento e morte. Trata-se de um ser que só pode se realizar nesse estar lançado entre um início e um fim. Heidegger denomina acontecimento a atualização desse estar lançado. Procurando desvendar os fundamentos ontológicos de nossa compreensão cotidiana da temporalidade, o pensador busca entender por que, ao falarmos de história, tendemos a reduzi-la ao passado (o ser para o princípio), tomado como sua dimensão mais fundamental. Da mesma forma, ao não compreendermos o caráter temporal do humano, somos levados a imaginá-lo como algo simplesmente dado no tempo, quase como um continente, algo da dimensão do espaço. O homem teria uma história porque está no tempo, sendo essa qualidade algo externo e distinto do que ele mesmo é e que a ele pode ou não ser acrescentada como um acidente. Entende-se assim outro paradoxo da compreensão cotidiana que confunde existência/realidade com o ser-no-presente, levando à conclusão lógica de que o que já não está presente (o passado) e o que ainda não está presente (o futuro) não existiriam. Com isso, a permanência no tempo (identidade) torna-se um grande mistério. Afinal, como algo pode permanecer, ou seja, costurar esses dois pontos de fuga que se tornam passado e futuro?

Heidegger descreve fenomenologicamente a concepção cotidiana de um homem "no tempo" para afirmar a derivação da historicidade da temporalidade como modo de ser do homem, algo, portanto, que lhe é interno. A historicidade deveria ser compreendida como a temporalização da temporalidade humana, ou, em outras palavras, a efetivação dessa condição estrutural do humano, o tempo histórico. No acontecer histórico, o primado do passado é uma espécie de ilusão derivada da concentração metafísica no presente, pois todo acontecer como propriamente humano é sempre uma temporalização, ou seja, "o vigor de ter sido enquanto algo atualizante e por vir" (HEIDEGGER 1996, p. 186).

Heidegger chama de historicidade própria a possibilidade de o homem reconhecer a natureza modalizante (enlaçamento de passado/futuro na abertura do agora) do seu acontecer, contrapondo-a à historicidade imprópria, em que o homem imagina-se "no tempo", ocultando o seu caráter internamente constitutivo. ${ }^{3}$ É no ser com os outros que a historicidade própria se realiza mais profundamente, o que Heidegger chama de "envio" comum: "O envio comum dos destinos da pre-sença [homem] em e com a sua 'geração' constitui

\footnotetext{
2 Neste artigo utilizo de forma livre a tradução de Márcia de Sá Cavalcante, simplificando-a em alguns momentos para facilitar a legibilidade para os leitores não familiarizados com o texto e seu vocabulário. Assim, ao tomar "pre-sença" (Dasein) por "homem", não estou desconhecendo os problemas dessa aproximação, muito menos a própria resistência de Heidegger em aceitá-la.

3 Neste sentido, parece improcedente a crítica de Ricoeur (1997, p. 154-155) de que haveria em Ser e tempo uma concentração no futuro em substituição à concentração agostiniana no presente. O que a análise pretende demonstrar é que uma compreensão mais original da temporalidade não pode se concentrar em apenas um momento temporal, mas em seu cruzamento, que marca o acontecer, ou, no entre nascimento e morte, esse é o cerne do argumento de Heidegger nesses artigos.
} 
o acontecer pleno e próprio da pre-sença" (HEIDEGGER 1996, p. 190). Mais adiante, a questão fica evidente:

\begin{abstract}
O ente que, em seu ser, é essencialmente porvir, de tal maneira que, livre para a sua morte [fim], nela pode se despedaçar [liberdade] e se deixar relançar para o fato de seu pré [aí, realidade] é um ente que, sendo porvir |futuro], é de modo igualmente originário o vigor de ter sido [passado que ainda vigora]. Somente este ente, transmitindo para si mesmo a possibilidade herdada, pode assumir o seu próprio estar-lançado e, neste instante, ser para o "seu tempo" (HEIDEGGER 1996, p. 191).
\end{abstract}

Nessa passagem nos interessa a distinção entre um possível "estar no tempo" e um "ser para o seu tempo". Esse tempo sempre "nosso" é a definição mais ampla que poderíamos dar do campo de fenômenos que pode ser tematizado por uma história da historiografia como analítica da historicidade, de como a "abertura historiográfica da história" (HEIDEGGER 1996, p. 181) está assentada nas condições gerais e formas de produção do "nosso tempo", seja no envio comum próprio, no qual essa vinculação é revelada, seja no impróprio, que predomina a maior parte das vezes.

Sempre somos a nossa história e é por esta "identidade" que podemos nos relacionar com ela por meio de uma ciência da história. O risco inerente a toda ciência é tomarmos a multiplicação dos objetos históricos como toda a história, e não como apenas um modo de nos relacionarmos com ela. Esse fascínio é irresistível porque cria a sensação, propriamente moderna, de se estar livre do passado e poder simplesmente colecioná-lo como uma espécie de repertório inerte e neutro.

Heidegger demonstra como a noção de contexto da moderna ciência histórica está enraizada na historicidade imprópria ${ }^{4}$ já que pressupõe que o homem precisa ser "recontextualizado", quando, na realidade, ele é sempre ser com, ou seja, em-um-mundo em "seu tempo". Concebendo a si mesmo como um ser no tempo, o homem imagina-se perdendo tempo, e essa sensação é resolvida na busca de uma "atualização" e de uma compreensão desse passado que se perde a partir do único ponto que imagina sólido, o presente. A historicidade própria, no entanto, deve produzir justamente o contrário, isto é, a desatualização do hoje:

Perdido na atualização do hoje, o impessoal compreende o "passado" a partir do "presente". A temporalidade da historicidade própria, ao contrário, enquanto instante que antecipa e repete, é uma desatualização do hoje e uma desabituação dos hábitos impessoais. Carregada dos despojos do passado que se Ihe tornaram estranhos, a existência impropriamente histórica busca, por sua vez, o moderno. A historicidade própria compreende a história como o "retorno" do possível e sabe, por isso, que a possibilidade só retorna caso, num instante do destino, a existência se abra para a possibilidade, numa repetição [transmissão] decidida (HEIDEGGER 1996, p. 198).

\footnotetext{
${ }^{4}$ As expressões "próprio" e "impróprio", ou "autêntico" e "inautêntico", "existencial" e "existenciário", "ôntico" e "ontológico" não devem ser tomadas, em Ser e tempo, como categorias valorativas, mas como descrição de diferentes níveis de análise da realidade. Aqui, novamente, Ricoeur (1997, p. 107 et seq) parece mais obscurecer do que liberar o debate, quando insiste em uma suposta hierarquização estanque dessas categorias.
} 
E ainda:

[...] a historiografia não parte, de forma alguma, do "presente" e de uma "realidade" que só se dá hoje para, tateando, recuperar um passado. A abertura historiográfica também se temporaliza a partir do porvir. A "seleção" do que deve se tornar objeto possível da historiografia já foi feita na escolha existenciária e fatual da historicidade, onde somente a historiografia surge e unicamente é (HEIDEGGER 1996, p. 202).

A analítica da historiografia teria como objeto próprio pensar as diferentes formas de acesso ao passado e como a experiência histórica revelada nesses momentos pode ser atingida por uma investigação das formas de continuidade e descontinuidade, isto é, de transmissão. Portanto, a transformação do tempo em tempo histórico ${ }^{5}$ pode ser pensada como o campo de fenômenos que poderia orientar a construção de agendas de investigação de longo prazo para uma História da Historiografia com relativa autonomia. Voltada para esse amplo campo de fenômenos, a História da Historiografia teria necessariamente de recorrer a uma variedade de objetos de investigação, cada um deles somente operacional a partir de suas teorias regionais.

Ao tornar a produção/emergência do tempo histórico como sua identidade mais ampla, a história da historiografia poderia superar o destino de ser apenas uma atividade auxiliar da historiografia geral e se libertar, assim, do risco de se tornar um discurso legitimador de práticas historiográficas, quando sua possibilidade mais profunda seria justamente a contrária, isto é, a de contribuir para uma destruição, em sentido positivo, do discurso e dos objetos historiográficos com o propósito de nos manter abertos para a experiência e o pensar da história.

A historiografia como ciência é, por definição, uma máquina de impropriedade, de transformação do tempo histórico em objeto pronto para os mais diversos usos sociais. Se aceitamos que uma das causas do "presente lento" (GUMBRECHT 2010) ${ }^{6}$ é uma espécie de efeito colateral do próprio discurso histórico moderno e, nesse sentido, impossível de ser superado em seu âmbito, já que sua função principal é justamente reificar (objetificar) o tempo histórico - daí o primado atual do discurso construtivista de "invenção da história" -, vemos a importância de um olhar não historicizante sobre a historiografia. Dito de outra forma, as condições que prefiguram a escrita da história não são apenas condições historiográficas, mas são também ontológico-existenciais.

Em sua reflexão mais recente, Hans Ulrich Gumbrecht descreve a situação contemporânea de se viver em um mundo entulhado de representações e narrativas sobre o passado, mas, ao mesmo tempo, perceber-se aprisionado em um presente desconectado dos passados e futuros abertos por esse

\footnotetext{
${ }^{5}$ A contribuição recente mais decisiva para uma teoria do tempo histórico de uma perspectiva historiográfica foi dada por Reinhart Koselleck a partir da incorporação do debate fenomenológico. Essa abertura teórica tem permitido grandes avanços em termos de pesquisas em história da historiografia ou sobre a experiência geral do tempo histórico.

${ }^{6} \mathrm{O}$ debate em torno da emergência de uma situação temporal nova nas últimas décadas já é bastante antiga, data pelo menos do final da década de 1970. O que François Hartog tem chamado de "presentismo" dialoga com esse contexto, em especial com o trabalho pioneiro de Pierre Nora. É difícil precisar os contornos da categoria nos textos de Hartog, que, às vezes, consiste na simples repetição do tema nostálgico da perda da utopia.
} 
conhecimento. Afirma o autor, assumindo um tom autobiográfico, que a vontade de uma experiência física do passado cresce justamente pela sensação de "[...] existir em um mundo cotidiano que frequentemente falha em nos envolver e acolher fisicamente. O desejo por atmosfera e clima é um desejo por presença - talvez uma variante que pressupõe o prazer em lidar com o passado cultural" (GUMBRECHT 2012a, posição 352). ${ }^{7}$

Essa emergência de interesse por certos climas históricos do passado parece obedecer a mecanismos que relacionam passado, presente e futuro e que, geralmente, escapam à ciência histórica. Assim, em cada presente podem ressoar com diferentes intensidades climas do passado sem que se possa estabelecer um efeito acumulativo ou evolutivo. Para Gumbrecht, certos textos e objetos que vêm do passado podem corporificar climas históricos, no sentido literal da expressão, de modo que, para além de serem tomados como representação, expressão ou documento de um passado morto, são também fonte de efeitos de imediaticidade desses mundos da vida evocados e são constantemente visados pelo presente quando se desloca a modulação entre passados e futuros possíveis: "No melhor dos casos podemos amplificar a impressão de preenchimento/realização que eles produzem - não os efeitos de uma edificação de uma sabedoria semifilosófica, mas a concretude intensa da experiência que essas obras tornam possível" (GUMBRECHT 2012a, posição 1184).8 Não é difícil ver que tal procedimento, mesmo não sendo único ou exclusivo, pode ser capturado por uma analítica da historicidade em seu esforço de produzir comentários e intensificar obras, objetos e eventos historiográficos em seus horizontes temporais.

Como a historicidade própria não é um privilégio de uma ciência histórica, mas algo inscrito no próprio ser do homem, uma história da historiografia como analítica da historicidade não pode se limitar a uma história da ciência histórica. Uma analítica da historicidade deverá investigar as condições, formas e funções das "aberturas historiográficas da história", e essas aberturas são sempre produzidas em uma tensão entre suas condições estruturais e os eventos. Assim, tal analítica teria como uma de suas principais funções desobstruir a historiografia de sua impropriedade, ou, dito de outra forma, colaborar para recolocar o historiador frente ao fenômeno da história por meio da desnaturalização das representações e objetos históricos que se acumulam como resultado da própria ciência; lembrar, enfim, ao historiador que nossa relação com o passado, embora necessariamente mediada por representações reificadas, tem outra fonte mais fundamental, a própria experiência da história.

O estudo da formação da historiografia como disciplina científica - uma espécie de história da ciência histórica - é apenas a parte mais recente e visível de uma história da historiografia; sua parte mais profunda e promissora reside

\footnotetext{
7 "The yearning for Stimmung has grown, because many of us - perhaps older people, above all - suffer from existence in an everyday world that often fails to surround and envelop us physically. Yearning for atmosphere and mood is a yearning for presence - perhaps a variant hat presupposes a pleasure in dealing with the cultural past" (GUMBRECHT 2012a, location 352).

8 "In the best of cases, we can amplify the impression of fullness they produce - not effects of edifying, half-philosophical wisdom, but the intensive concreteness of the experience that the work makes possible" (GUMBRECHT 2012a, location 1184).
} 
justamente no estudo do enraizamento dessas formas de conhecimento do passado no próprio tempo histórico. Um dos desafios da comunidade é não se limitar a uma mera descrição desses fenômenos, mas compreender as suas formas de produção e suas lógicas de transformação. Esse alargamento de seu escopo pode permitir incorporar de modo mais decisivo e coerente a variedade de recortes e fontes necessárias para se aproximar desse amplo e decisivo campo de fenômenos a partir de um viés analítico-historiográfico. Essa ampliação de objetos, que já é visível nas pesquisas, permitiria pensar a historiografia em suas relações com outros fenômenos da historicidade que a emolduram e condicionam os mundos da vida e que hoje se multiplicam rapidamente, como as imagens, o audiovisual e as mais variadas formas de comunicação que emergem da mesma abertura temporal/historicidade que possibilita a historiografia.

Esse projeto, sempre em aberto, de uma disciplina historiográfica (e anti-historiográfica) dedicada ao estudo do tempo histórico só terá sentido ou viabilidade se os seus praticantes estiverem dispostos a construir e reconstruir suas condições teóricas gerais, ou seja, a elaborar uma teoria geral da historicidade. Toda vez que fazemos algo que chamamos de história da historiografia estamos, em maior ou menor grau, pressupondo uma teoria da historicidade. Essa teoria pressuposta responde por perguntas como: de que modo esse fenômeno se transforma a ponto de ser possível e necessário contar a sua história? O que é historiografia? Qual é sua relação com os outros fenômenos históricos que conseguimos identificar? De que modo essa atividade se diferencia de outras? Para escrever essa história basta contar com a resposta que naturalmente temos; mas, para escrevê-la bem, para realizar de forma adequada a fusão de horizontes entre nossas definições atuais e as contidas na própria história que tentamos contar, precisamos retirar dela mesma as condições para um maior esclarecimento conceitual. O trabalho de melhor conhecer a historiografia não pode se encerrar na sua descrição, mas deve avançar hermeneuticamente, ou seja, de modo circular, para atingir as condições que permitem a própria descrição.

Enfrentar o debate e a disputa político-institucional em todos os níveis e complexidade que escapam ao campo da ciência é uma tarefa difícil. Nas condições atuais podemos escolher o caminho da santidade da recusa do mundo, mas não podemos nos retirar dele como faziam os eremitas medievais e antigos, pois Deus está morto e levou consigo a possibilidade desse tipo de santidade. Negar esse enfrentamento hoje não leva à santidade, mas ao consumo; significa desistir de assumir o ônus pela produção do mundo e sua preservação para apenas comprar o que nos é oferecido. Além de pouco complexa, essa nova forma de negação do mundo pelo consumo tem como seu limite o fato de que, como consumidores, os nossos desejos de compra já foram definidos previamente pelo sistema do mercado.

Por isso, por mais complexa e problemática que seja a tarefa de afirmação de uma autonomia disciplinar, para além de seus resultados institucionais, ela só pode se justificar e garantir sua legitimidade se fizer avançar de modo significativo nosso conhecimento sobre a realidade. A autonomia não pode ser apenas uma reivindicação; ela pressupõe a decisão de investir como destino 
uma história (passado) que se abre para muitas possibilidades. Um dos seus indicadores fundamentais, para usar de modo pragmático elementos da definição de sistema de Niklas Luhmann, é sua capacidade de descrever o seu ambiente em uma linguagem própria. Para a história da historiografia, esse teste significa perguntar se estamos ou não caminhando para a tradução-redescrição de problemas históricos não historiográficos em uma linguagem historiográfica. Trata-se, enfim, da capacidade de redescrever no interior de nossa cultura disciplinar os grandes embates de nossa história.

\section{Referências bibliográficas}

ARAUJO, Valdei Lopes de. Sobre o lugar da história da historiografia como disciplina autônoma. Locus, Juiz de Fora, V. 12, p. 79-94, 2006. Disponível em: http://www.ufjf.br/locus/files/2010/02/42.pdf.

- História dos Conceitos: problemas e desafios para uma releitura da modernidade Ibérica. Almanack Braziliense (Online), V. 7, p. 4755, 2008. Disponível em: http://www.almanack.usp.br/PDFS/7/07_ Forum-02.pdf.

. O século XIX no contexto da redemocratização brasileira: a escrita da história oitocentista, balanço e desafios. In ; OLIVEIRA, Maria da Glória de (org.). Disputas pelo passado: história e historiadores no Império do Brasil. Ouro Preto: Edufop/PPGHIS, 2012.

GUMBRECHT, Hans Ulrich. Atmosphere, Mood, Stimmung: on a hidden potential of Literature. Stanford, Ca: Stanford University Press, 2012a.

. Nach 1945: Latenz als Ursprung der Gegenwart. Berlim: Suhrkamp, 2012b.

- Lento presente: sintomatología del nuevo tiempo histórico. Madrid: Escolar y Mayo, 2010.

- A presença realizada na linguagem: com atenção especial para a presença do passado. História da Historiografia. Ouro Preto, no 03, p. 10-22, setembro 2009. Disponível em: http://www.historiadahistoriografia.com. $\mathrm{br} / \mathrm{revista/article/view/68/30.}$

HEIDEGGER, Martin. Ser e tempo. Petrópolis: Vozes, 1996. Parte II.

RICOEUR, Paul. Tempo e narrativa. São Paulo: Papirus, 1997. Tomo III.

RODRIGUES, Henrique Estrada; NICOLAZZI, Fernando. Entrevista com François Hartog: história, historiografia e tempo presente. História da Historiografia. Ouro Preto, no 10, p. 351-371, dezembro 2012. Disponível em: http://www.historiadahistoriografia.com.br/revista/ article/view/478/331.

RÜSEN, Jörn. Como dar sentido ao passado: questões relevantes de metahistória. História da Historiografia. Ouro Preto, no 02, p. 163-209, março, 2009. Disponível em: http://www.historiadahistoriografia.com. $\mathrm{br} /$ revista/article/view/12/12. 